\title{
Preparation and Characterization of Nitridation Layer on 4H SiC (0001) Surface by Direct Plasma Nitridation
}

\author{
Yoshiyuki Akahane ${ }^{1 *}$, Takuo Kano ${ }^{1}$, Kyosuke Kimura$^{1}$, Hiroki Komatsu, \\ Yukimune Watanabe, Tomohiko Yamakami, Kiichi Kamimura1, a \\ ${ }^{1}$ Department of Electrical and Electronic Engineering,
}

Shinshu University, 4-17-1 Wakasato, Nagano 380-8553, Japan

a kamimur@shinshu-u.ac.jp

Keywords: Nitride, MIS, TEOS

\begin{abstract}
A nitride layer was formed on a $\mathrm{SiC}$ surface by plasma nitridation using pure nitrogen as the reaction gas at temperatures from $800^{\circ} \mathrm{C}$ to $1400^{\circ} \mathrm{C}$. The surface was characterized by XPS. The XPS measurement showed that an oxynitride layer was formed on the SiC surface by plasma nitridation. The high process temperature seemed to be effective to activate the nitridation reaction. A $\mathrm{SiO}_{2}$ film was deposited on the nitridation layer to form $\mathrm{SiO}_{2} /$ nitride/SiC structure. The interface state density of the $\mathrm{SiO}_{2} /$ nitride/ $\mathrm{SiC}$ structure was lower than that of the $\mathrm{SiO}_{2} / \mathrm{SiC}$ structure. This suggested that the nitridation was effective to improve the interface property.
\end{abstract}

\section{Introduction}

The formation of $\mathrm{SiO}_{2}$ layer on $\mathrm{SiC}$ by the conventional oxidation is one of the attracting factors of $\mathrm{SiC}$ as a material for power electronics devices. The high densities of interface states are believed to be responsible for the low inversion channel mobility in n-channel metal-oxide semiconductor field effect transistors (MOSFETs). Many efforts have been carried out to reduce or to passivate these interface states. It has been reported that such interfacial defects can be passivated effectively by nitridation in nitric oxide (NO) ambient [1].

However, the density of interface states at $\mathrm{SiO}_{2} / \mathrm{SiC}$ interfaces has remained one or two orders of magnitude larger than that at $\mathrm{SiO}_{2} / \mathrm{Si}$ interfaces. Silicon nitride is another candidate for the insulating layer of SiC MIS devices. Few papers have reported about nitridation of SiC surface. We have proposed that a direct nitridation layer might be a candidate for $\mathrm{SiC}$ passivation $[2,3,4]$. Shirasawa et al. reported on the formation of an epitaxial silicon oxynitride ( $\mathrm{SiON}$ ) layer on a $6 \mathrm{H}-\mathrm{SiC}(0001)$ surface, which offers great potential for device applications [5]. Devyncka et al. focused on the electronic properties of the interface structure composed of an epitaxial silicon oxynitride layer on $6 \mathrm{H}-\mathrm{SiC}$ (0001), using a density functional scheme[6].

We have tried to form an insulating nitride layer on $\mathrm{SiC}$ by direct nitridation[2,3,4]. Chai et al also reported a $\mathrm{Si}_{3} \mathrm{~N}_{4}$ passivation layer grown on the $4 \mathrm{H}-\mathrm{SiC}(0001)$ surface by direct atomic source nitridation at various substrate temperatures [7]. Although the direct nitridation seemed to be an attractive method to form insulating layer on $\mathrm{SiC}$, it has been difficult to get the nitride layer thicker than several $\mathrm{nm}$ by direct nitridation method.

In this work, we have tried to form a nitride layer through exposure of $\mathrm{SiC}$ surfaces to nitrogen glow discharge plasma. A nitridation layer has been successfully grown on the $4 \mathrm{H}-\mathrm{SiC}(0001)$ surface by this method. The chemical property of the nitridation layer was measured by X-ray photoelectron spectroscopy (XPS). However, the thickness of the nitride layer was several $\mathrm{nm}$ and too small to prepare the sample for the the capacitance-voltage $(\mathrm{C}-\mathrm{V})$ measurement. $\mathrm{A} \mathrm{SiO}_{2}$ layer was formed on the nitride layer by chemical vapor deposition (CVD) method using tetraethoxysilane (TEOS) to obtain sufficient thickness for interface characterization by $\mathrm{C}-\mathrm{V}$ method. The $\mathrm{C}-\mathrm{V}$ characteristics were measured at $1 \mathrm{MHz}$ to evaluate interface properties. 


\section{Experimental}

The substrate was a (0001) Si face of an epitaxial 4H-SiC obtained from Cree. The donor concentration was $1.5 \times 10^{16} \mathrm{~cm}^{-3}$. Immediately before the nitridation, the substrate was immersed in buffered HF to remove the native oxide on the surface. The nitridation was carried out in the glow discharge of pure nitrogen. The plasma was excited by an inductively coupled RF power of $40 \mathrm{~W}$ at 13.56 MHz. The reaction was carried out under the pressure of $30 \mathrm{~Pa}$. The water cooled quartz tube was used as the reaction chamber. The substrate holder was made from graphite block and was heated by an inductively coupled RF power of $85 \mathrm{kHz}$ up to $1400^{\circ} \mathrm{C}$. The substrate temperature was measured by a pyro thermometer. The nitridation was carried out at room temperature and at temperature between $800^{\circ} \mathrm{C}$ to $1400^{\circ} \mathrm{C}$ for $15 \mathrm{~min}$. The $\mathrm{SiO}_{2}$ layer was deposited by the chemical vapor deposition using the TEOS as a source material to form the $\mathrm{SiO}_{2} /$ nitride/SiC structure with the insulating layer of enough thickness for the $\mathrm{C}-\mathrm{V}$ measurement. Aluminum was evaporated to form a MIS diode. MIS diodes without nitride layer $\left(\mathrm{SiO}_{2} / \mathrm{SiC}\right.$ structure $)$ were also prepared to examine the effect of nitridation on the interface property. In this case, the $\mathrm{SiO}_{2}$ layer was deposited directly on the $\mathrm{SiC}$ surface by TEOS CVD, immediately after the treating the SiC surface with buffered HF. The TEOS CVD was carried out at $750^{\circ} \mathrm{C}$ for $15 \mathrm{~min}$. The thickness of the $\mathrm{SiO}_{2}$ layer was estimated to be about 90nm.

The XPS measurement was carried out to characterize the direct nitridation layer. The $\mathrm{C}-\mathrm{V}$ characteristics of $\mathrm{SiO}_{2} /$ nitride/ $\mathrm{SiC}$ MIS diodes and those of $\mathrm{SiO}_{2} / \mathrm{SiC}_{\mathrm{CIS}}$ diodes were measured at 1 $\mathrm{MHz}$ to evaluate interface properties.

\section{Results and Discussions}

Figure 1 shows XPS spectrum from the plasma nitridation layer on SiC. Small peaks corresponding to N1s signal were appeared in the XPS spectrum as shown in Fig. 1. This suggested that a thin nitride layer was formed on $\mathrm{SiC}$ surface by the plasma nitridation. Although pure nitrogen was used as the reaction gas, the peak from O1s appeared in the XPS spectrum as shown in Fig. 1. The residual oxygen seemed to result in the formation of oxynitride layer by the plasma nitridation, because the background pressure was about $0.24 \mathrm{~Pa}$, even if the careful purging was carried out before the nitridation. The intensity of the O1s peak slightly decreased after the sputter etching with Ar ion in the XPS chamber.

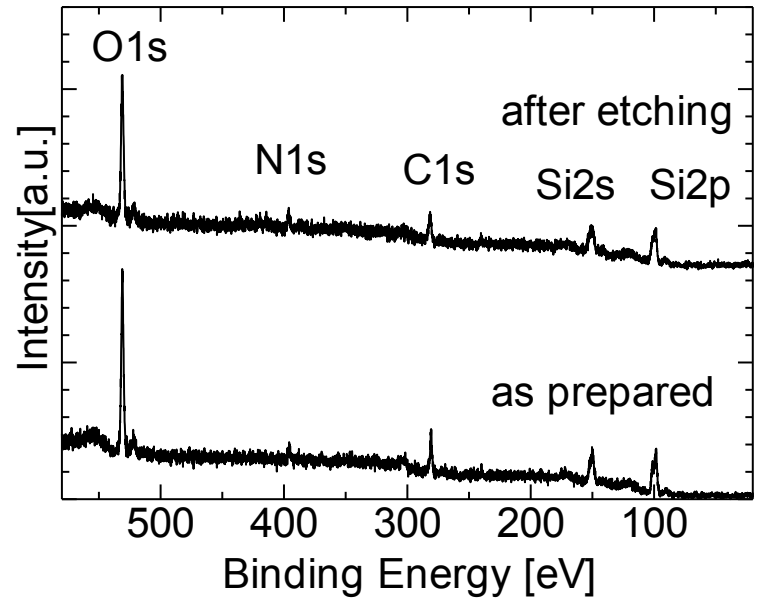

Fig. 1 XPS spectra from SiC surface after the direct plasma nitridation at the substrate temperature of $1200^{\circ} \mathrm{C}$.

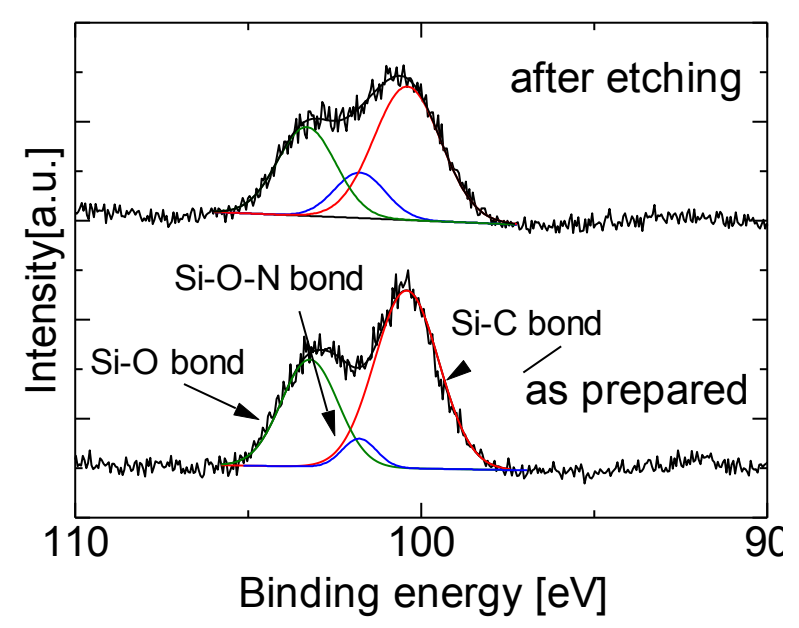

Fig. 2 XPS spectra near the Si2p peak from $\mathrm{SiC}$ suface after the nitridation at the substrate temperature of $1200^{\circ} \mathrm{C}$. 


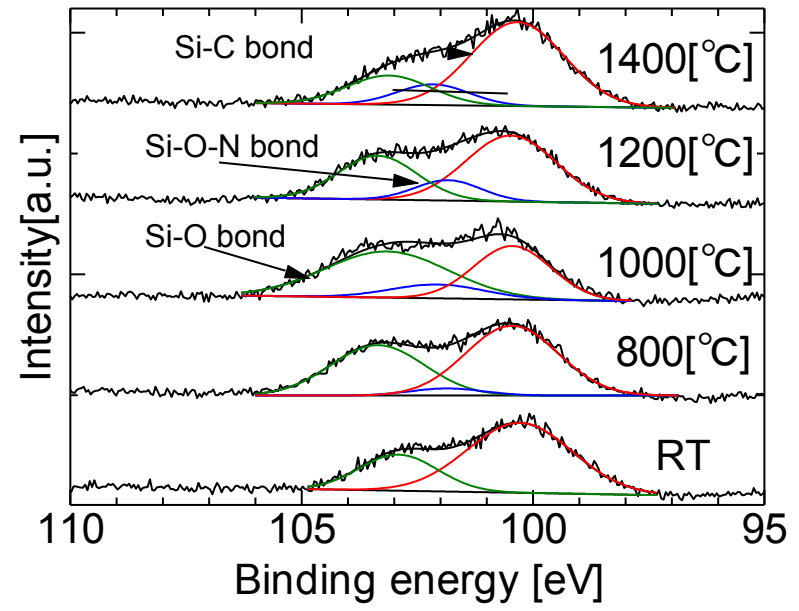

Fig. 3 XPS spectra near Si2p peaks from SiC surface after the nitridation at the substrate temperture from RT to $1400^{\circ} \mathrm{C}$. The surface was etched with Ar ion for $5 \mathrm{sec}$.

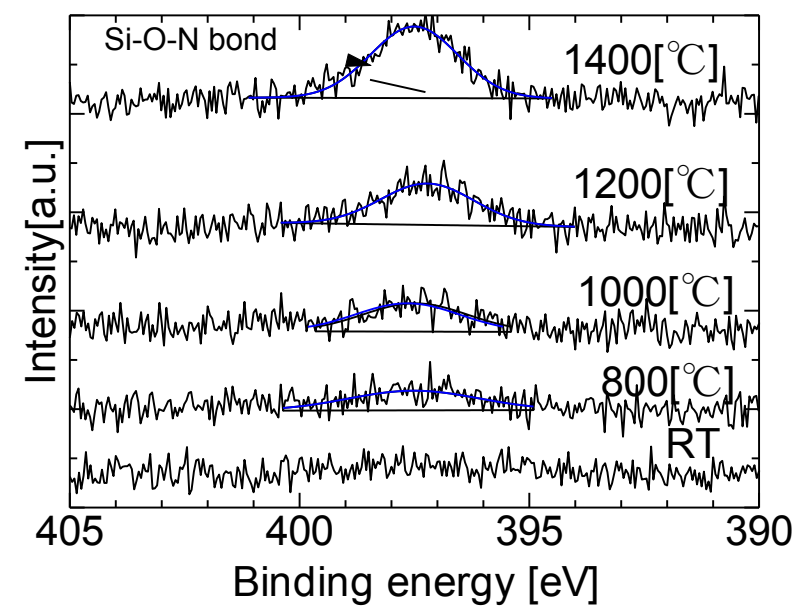

Fig. 4 XPS spectra near N1s peaks rom SiC surface after the nitridation at the substrate temperture from RT to $1400^{\circ} \mathrm{C}$. The surface was etched with Ar ion for $5 \mathrm{sec}$.

Figure 2 shows the XPS spectrum from Si2p. The peak seemed to consist of Si-O, Si-O-N and Si-C bond. The component corresponding to $\mathrm{Si}-\mathrm{C}$ bond was observed in the $\mathrm{Si} 2 \mathrm{p}$ peak form the nitride layer. This was because the nitride layer was so thin that the photo electron from the substrate appeared at the surface of the sample through the nitride layer. The intensity of the peak corresponding to Si-O bond also slightly decreased after sputter etching the surface by Ar ion. This suggested that the surface of the nitride layer was oxidized during the transportation of the sample from the reaction chamber to the XPS chamber in the air.

Figure 3 shows the Si2p spectrum of the samples prepared at the temperature form $800^{\circ} \mathrm{C}$ to $1400^{\circ} \mathrm{C}$, and at room temperature. The intensity of the peak from Si-O bond decreased and that of the peak from Si-N increased with the increasing process temperature. Figure 4 shows N1s peaks from the surface of the nitride sample at temperature from $800^{\circ} \mathrm{C}$ to $1400^{\circ} \mathrm{C}$, and at room temperature. The high process temperature seemed to be effective to activate the nitridation reaction. The temperature of $1400^{\circ} \mathrm{C}$ was almost the upper limit of the nitridation system used in this work.

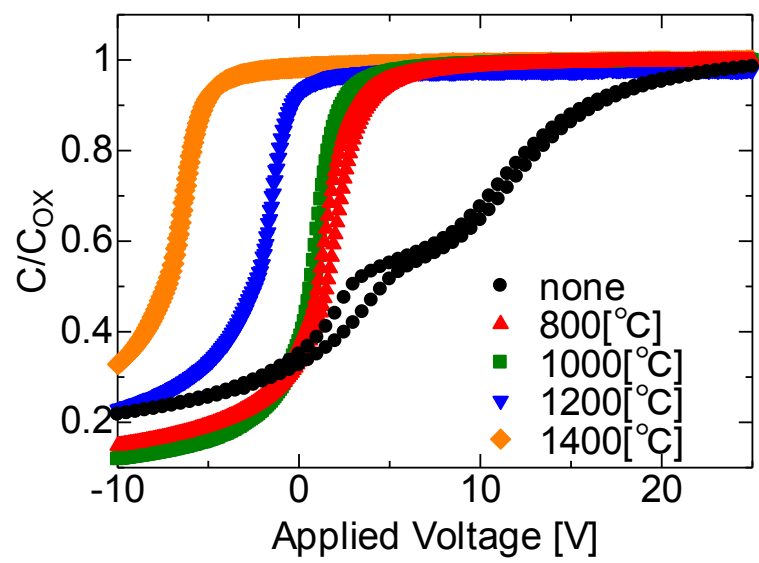

Fig. 5 High frequency $\mathrm{C}-\mathrm{V}$ curves of $\mathrm{SiO}_{2} /$ nitride/SiC MIS diodes and a $\mathrm{SiO}_{2} / \mathrm{SiC}$ MIS diode.

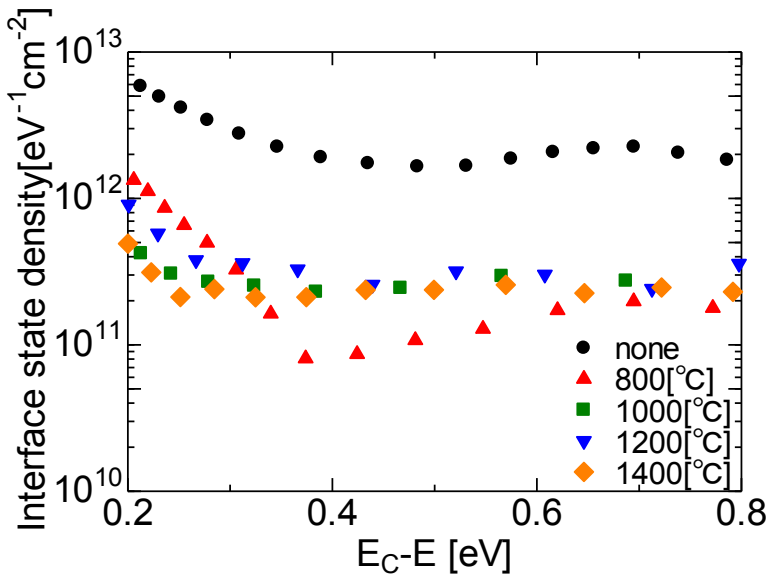

Fig. 6 Interface state densities of $\mathrm{SiO}_{2} /$ nitride/ $\mathrm{SiC}$ MIS structure and $\mathrm{SiO}_{2} / \mathrm{SiC}$ MIS diode estimated from $\mathrm{C}-\mathrm{V}$ curves shown in Fig. 5. 
Figure 5 shows $\mathrm{C}-\mathrm{V}$ curves of the samples prepared at temperatures from $800^{\circ} \mathrm{C}$ to $1400^{\circ} \mathrm{C}$, and also that of the sample without nitridation layer. The closed circles indicate the data of MIS diode without nitridation layer. The flat band voltage shifted toward the negative direction with increasing process temperature. The value of flat band voltage indicated that positive charges were formed near the interface by plasma nitridation at the higher temperature than $1200^{\circ} \mathrm{C}$. C-V curves suggested that the interface property was improved by the plasma nitridation. Figure 3 and 4 indicate the Si-O-N bond or the nitrogen content increased as increasing the nitridation temperature. This may have some effect on the improvement of interface property.

The interface state density was estimated from these curves by Terman method to discuss the effect of the substrate temperature on the interface property. This method has been thought to contain inaccuracy especially near the conduction band, but it may be useful for the discussions based on relative comparisons. Figure 6 shows the interface state density estimated from the C-V curves shown in Fig. 5. The closed circles indicate the interface state density of MIS diode without nitridation layer. The interface state densities of $\mathrm{SiO}_{2} /$ nitride/ $\mathrm{SiC}$ structures were almost one order of magnitude lower than that of the $\mathrm{SiO}_{2} / \mathrm{SiC}$ suture. It was apparent that the nitridation was effective to reduce the interface state density. It was difficult to discuss the result by comparing with reported values obtained by other methods such as $\mathrm{NO}$ annealed $\mathrm{SiO}_{2}$, because of the inaccuracy of Terman method.

\section{Summary}

The XPS measurement showed that the oxynitride layer was formed on the SiC surface by plasma nitridation. The high process temperature seemed to be effective to activate the nitridation reaction. The result suggested that the nitridation was effective to improve the interface property.

\section{Acknowledgement}

A part of this work was supported by JSPS KAKENHI Grant Number 24560371.

\section{References}

[1] G. Y. Chung, C. C. Tin, J. R. Williams, K. Mcdonald, M. Di Ventra, S. T. Pantelides, L. C. Feldman, and R. A. Waller, Appl. Phys. Lett. 76, 1713 (2000).

[2] L. YingShen, S. Hashimoto, K. Abe, R. Hayashibe, T. Yamakami, M. Nakao, and K. Kamimura: Jpn. J. Appl. Phys. 44, 673 (2005).

[3] Y. Ishida, C. Chen, M. Hagihara, T. Yamakami, R. Hayashibe, K. Abe and K. Kamimura: Jpn. J. Appl. Phys. 47, 676 (2008).

[4] M. Hemmi, T. Sakai , T. Yamakami, R. Hayashibe and K. Kamimura, Materials Science Forum Vols. 740-742, 805 (2013).

[5] T. Shirasawa, K. Hayashi, S. Mizuno, S. Tanaka, K. Nakatsuji, F. Komori, and H. Tochihara, Phys. Rev. Lett. 98, 136105 (2007).

[6] F. Devyncka, Ž. Šljivančanin and A. Pasquarello, Appl. Phys. Letters, 91, 061930 (2007).

[7] J. W. Chai, J. S. Pan, Z. Zhang, S. J. Wang, Q. Chen and, C. H. AHuan, Appl. Phys. Letters, 92 332811 (2008). 